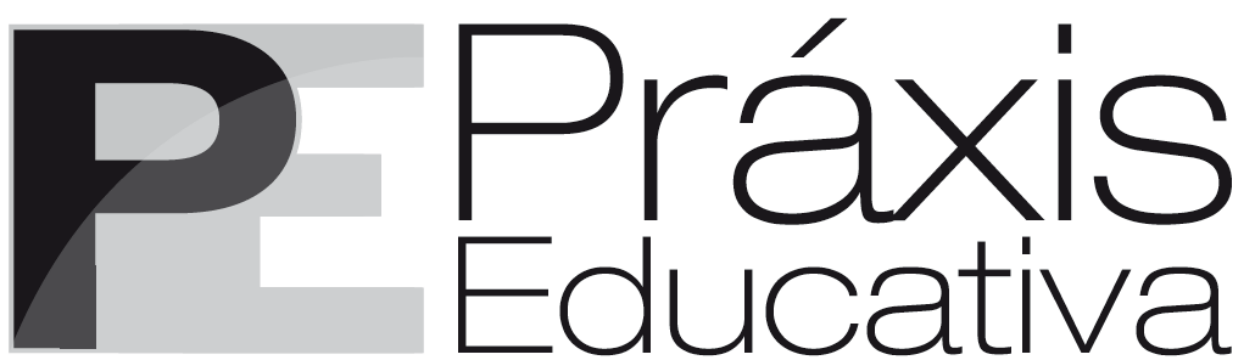

ISSN 1809-4309 (Versão online)

DOI: 10.5212/PraxEduc.v.12i2.0021

\title{
A concepção de Pedagogia Social na formação dos Educadores Sociais na
}

Espanha

\section{The conception of Social Pedagogy in the training of Social Educators in Spain}

\author{
La concepción de Pedagogía Social en la formación de los Educadores \\ Sociales en España
}

Érico Ribas Machado*

\begin{abstract}
Resumo: Este texto apresenta dados de pesquisa desenvolvida em estudo de doutorado a partir da perspectiva metodológica da Educação Comparada (GARCIA GARRIDO, 1986). Para que o objetivo da tese fosse alcançado, optou-se por análise de ementas das disciplinas de Pedagogia Social que compõem a proposta curricular do curso de Graduação em Educação Social de dez universidades espanholas, a saber: 1. Universidad Nacional de Educación a Distancia; 2. Universidad Autónoma de Barcelona; 3. Universidad Castilla de la Mancha; 4. Universidad Santiago de Compostela; 5. Universidad de Salamanca; 6. Universidad de Deusto; 7. Universidad de León; 8. Universidad de Valencia; 9. Universidad de Las Palmas de Gran Canarias; 10. Universidad de Málaga. Optou-se ainda por aliar à metodologia comparativa a análise de conteúdo (PEREZ SERRANO, 2003). A análise das ementas permitiu constatar uma persistente tentativa de caracterizar a Pedagogia Social como uma ciência que deva articular a teoria e a prática como essência para a formação do Educador Social.

Palavras-chave: Pedagogia Social comparada. Educador Social espanhol. Análise de conteúdo.
\end{abstract}

Abstract: This text presents research data developed in a doctoral study from the methodological perspective of Comparative Education (GARCIA GARRIDO, 1986). In order to achieve the thesis objective, we opted for the analysis of the Social Pedagogy disciplines syllabus that compose the curricular proposal of the Undergraduate Course in Social Education of ten Spanish universities, namely: 1. National University of Distance Education; 2. Autonomous University of Barcelona; 3. University of Castilla-La Mancha; 4. Santiago de Compostela University; 5. University of Salamanca; 6. University of Deusto; 7. University of León; 8. University of Valencia; 9. University of Las Palmas de Gran Canarias; 10. University of Málaga. We also opted to combine the content analysis with comparative methodology (PEREZ SERRANO, 2003). The analysis of the syllabuses permitted to verify a persistent attempt to characterize Social Pedagogy as a Science that should articulate theory and practice as essence for the formation of the Social Educator.

Keywords: Comparative Social Pedagogy. Spanish Social Educator. Content analysis.

\footnotetext{
* Professor da Universidade Estadual de Ponta Grossa. E-mail: <ericormachado@yahoo.com.br>.
} 
Resumen: Este texto presenta datos de investigación desarrollada en estudio de doctorado a partir de la perspectiva metodológica de la Educación Comparada (GARCIA GARRIDO, 1986). Para que el objetivo de la tesis fuera alcanzado, se optó por el análisis de los planes de estudio de las asignaturas de Pedagogía Social que componen la propuesta curricular del curso de Graduación en Educación Social de diez universidades españolas, a saber: 1. Universidad Nacional de Educación a Distancia; 2. Universidad Autónoma de Barcelona; 3. Universidad Castilla de la Mancha; 4. Universidad Santiago de Compostela; 5. Universidad de Salamanca; 6. Universidad de Deusto; 7. Universidad de León; 8. Universidad de Valencia; 9. Universidad de Las Palmas de Gran Canarias; 10. Universidad de Málaga. Se optó por aliar a la metodología comparativa el análisis de contenido (PEREZ SERRANO, 2003). El análisis de los planes de estudio permitió constatar un persistente intento de caracterizar a la Pedagogía Social como una ciencia que deba articular la teoría y la práctica como esencia para la formación del Educador Social.

Palabras clave: Pedagogía Social Comparada. Educador Social español. Análisis de contenido.

\section{Introdução}

Em 2014, no curso de Doutorado em Educação na Universidade de São Paulo - Brasil, foi defendida a tese intitulada $O$ desenvolvimento da Pedagogia Social sob a perspectiva comparada: o estágio atual no Brasil e Espanha, sob orientação do Professor Dr. Roberto da Silva e com bolsa de pesquisa CNPq. A tese teve como objetivo geral - investigar o processo de internacionalização da Pedagogia Social e suas repercussões no contexto espanhol e brasileiro, e como objetivos específicos - identificar o processo de internacionalização da Pedagogia Social; verificar a concepção de Pedagogia Social na formação dos Educadores Sociais na Espanha; e identificar a concepção de Pedagogia Social em construção no Brasil. Para que fossem alcançados os objetivos propostos, a metodologia foi organizada de maneira a dar conta dos diferentes processos de coleta e de análise de dados que foram necessários para a sua estruturação, tendo como perspectiva de fundo a abordagem comparativa.

Em um primeiro momento, por meio do percurso histórico detalhado, foi possível compreender como a área adentra o meio acadêmico tornando-se uma disciplina científica e de formação profissional. Especificamente para chegar ao segundo objetivo específico, optou-se por uma análise profunda das ementas das disciplinas de Pedagogia Social que compõem o quadro de formação do curso de Graduação em Educação Social de dez universidades espanholas.

Como procedimento metodológico para coleta e interpretação de dados, foi utilizada a análise de conteúdo que, de acordo com José Luis García Garrido (1986, p. 171), é importante auxílio para os estudos comparativos, pois permite uma análise objetiva, sistemática e quantitativa. A sequência de procedimentos para essa categorização foi amparada pela obra Investigación Cualitativa: métodos y técnicas, de autoria de Gloria Perez Serrano (2003).

É importante esclarecer que a pesquisa tomou determinado rumo devido ao estágio de doutorado realizado em Madri, em 2012-2013, com bolsa de pesquisa CAPES, junto à Universidad Nacional de Educación a Distancia, sob orientação da Professora Dra. Glória Perez Serrano. Época fundamental de aprofundamento de estudos que adentraram a literatura específica e elaborações conceituais significativas, que contribuíram para análise dos dados. Estas permitiram apresentar um aspecto relativo ao objetivo proposto que demonstra o que efetivamente se pretende com a disciplina Pedagogia Social e o que realmente parece ser efetivado com a mesma disciplina. O debate sobre formação teórica ou prática é o que teve maior destaque nas análises.

Práxis Educativa, Ponta Grossa, v. 12, n. 2, p. 657-681, maio/ago. 2017 Disponível em: <http://www.revistas2.uepg.br/index.php/praxiseducativa> 


\section{A Pedagogia Social como disciplina científica nas universidades espanholas}

Conhecer como a área se organizou - em primeiro lugar, como uma disciplina do currículo dos cursos de Pedagogia; depois, como uma graduação específica; e, atualmente, como uma área profissional devidamente estruturada - foi fundamental para realizar o estudo proposto.

Em 1954, a Pedagogia Social era ofertada como uma disciplina específica na Universidad de Madrid e foi a partir daquele ano que ela vem se desenvolvendo no meio acadêmico, com alguns percalços. Uma década após ser reconhecida como disciplina, ela foi deslocada para o campo da Sociologia da Educação, como explicam Quintana Cabanas (1997) e Perez Serrano (2004), por ser considerada a modalidade mais científica e atualizada, seguindo um modelo positivista das Ciências da Educação, orientada pelo enfoque Anglo-saxão, como esclarecem os pesquisadores Esteban, Caride Gomez e Úcar (2013).

Esse deslocamento, que durou em torno de uma década, modificou não apenas a nomenclatura, mas também seus conteúdos. De acordo com Perez Serrano (2004, p. 160), atrasou o desenvolvimento da Pedagogia Social, que voltou a recuperar-se e a fortalecer-se a partir dos anos oitenta. A autora explica que, no ano de 1988, o Grupo de Trabajo XV del Consejo de Universidades criou e regulamentou a proposta de formação em nível superior do Educador Social, surgindo o Título de Diplomado em Educação Social, com três anos de duração, orientando a formação de um educador que atuasse nos âmbitos não escolares e que seria uma formação mais voltada à prática e à técnica; e o título de Licenciado em Pedagogia Social, com cinco anos de duração, destinado à formação de um especialista em Educação Social, com uma formação mais teórica e científica.

Apenas em 1991, foi publicada a aprovação das diretrizes gerais próprias dos planos de estudos para obtenção do título em Diplomado em Educação Social. Essas diretrizes permitiram que essa formação fosse ofertada em todas as Comunidades Autônomas espanholas. Já o título de Licenciado em Pedagogia Social passou a ser ofertado por algumas universidades, como Universidade Central de Barcelona e das Ilhas Baleares, e funcionava como um nível superior aos diplomados. Dessa maneira, os diplomados em Educação Social, em Trabalho Social ou os professores da Educação Básica poderiam, por meio de complementações aos seus estudos, chegar na Graduação em Pedagogia Social.

Esse movimento permitiu que a Pedagogia Social fosse instalada nas universidades, dentro das Faculdades de Educação, como explica Perez Serrano (2004), gerando o fortalecimento da área e permitindo a criação de cursos de especialização, mestrado e doutorado, que abordassem temáticas relacionadas.

Durante a década de noventa, gestou-se um contexto novo que culminaria, já na primeira década dos anos dois mil, na modificação do Ensino Superior tanto na Espanha como em todos os países membros da União Europeia. Por consequência, a Diplomatura em Educação Social e a Graduação em Pedagogia Social passariam por reformulações profundas e assumiriam uma nova configuração.

Esse novo contexto foi a criação do Espaço Europeu de Ensino Superior, mais conhecido como o Processo de Bolonha, que surgiu a partir de discussões entre diferentes instâncias representativas dos diversos países, gerando documentos norteadores, dentre eles a Declaração de Bolonha (1999), que expressa objetivos a serem alcançados. Os objetivos propostos que dariam origem à criação do Espaço Europeu de Ensino Superior deveriam ser cumpridos até o ano de 2010, o que gerou uma ampla mobilização nos países da União Europeia, seguindo as suas orientações desse e de outros documentos que nortearam a reforma do Ensino

Práxis Educativa, Ponta Grossa, v. 12, n. 2, p. 657-681, maio/ago. 2017 Disponível em: <http://www.revistas2.uepg.br/index.php/praxiseducativa > 
Superior, em todos os seus aspectos, nos 47 países que passaram a compor esse novo contexto. No caso específico da Pedagogia Social na Espanha, essa orientação culminou em uma reestruturação minuciosa do que já estava implantado, mas que necessitava de uma reformulação para atender aos novos direcionamentos transnacionais.

Seguindo esse movimento da comunidade europeia, em 2005, a Espanha lançou seu Libro Blanco - Titulo de Grado en Pedagogía y Educacion Social, organizado, gestado e avaliado pela Agencia Nacional de Evaluación de la Calidad y Acreditación (ANECA). Esse documento resulta de um esforço em reformular as referidas titulações, agora atendendo às demandas do Espaço Europeu de Ensino Superior (EEES). Para chegar à proposta final, foram organizadas diferentes estratégias que agregaram 39 universidades espanholas e oito associações profissionais, com representantes que discutiram a reformulação das áreas da Pedagogia e da Educação Social. Foram criadas sete comissões para dar conta do trabalho proposto: análises comparadas dos estudos superiores da Educação na Europa (exceto formação de professores); as titulações de Pedagogia e Pedagogia Social nas universidades espanholas: planos de estudo e saídas profissionais; âmbitos e perfis profissionais no campo da Pedagogia e da Educação Social; competências profissionais e Pedagogia; competências profissionais e Educação Social; critérios e indicadores de qualidade no planejamento das titulações; Comissão de Coordenação "Rede Educação - Rede Magistério".

Especificamente no caso da Educação Social, após um amplo levantamento de diferentes dados que envolviam a Diplomatura em Educação Social, justificou-se a necessidade de reformulação, criando-se a Graduação em Educação Social, entendendo que o profissional que será formado atuará nas seguintes instâncias e áreas: Comunidades Autônomas; Prefeituras; Área de Serviços Sociais; Centros Sociosanitários para Terceira Idade; Centros para Inserção para o Trabalho; Equipes de Atenção à Infância e Adolescência em Risco Social; Centros Residenciais para crianças em Risco Social; Associações e Fundações de Atenção a Imigrantes e População com Dificuldades de Inserção Social; Associações e Fundações de Atenção a Personas com necessidades; Gestão Cultural (Animação Sociocultural, Ócio, Museus, Brinquedotecas); Escolas de Animadores Juvenis; Área de Meio Ambiente; Drogodependências.

Após os estudos realizados, também foram identificadas e estabelecidas as competências que caracterizam a formação e a existência do profissional. Essas competências são elaboradas a partir das orientações do Projeto Tuning, que serviram para repensar o currículo para formação nas universidades e que deverão congregar diferentes perspectivas. No documento, existe a defesa de que "[...] planejar estudos que permitam formar um profissional competente para o desempenho de suas funções é, evidentemente, uma ideia de grande potência teórica" (ANECA, 2005, p. 154).

Os argumentos presentes no documento também justificam que a lógica das competências permite a reflexão sobre o sujeito em processo de formação, considerando aspectos metodológicos que irão permitir acessar conhecimentos técnicos e acadêmicos que poderão ser colocados em prática. A proposta das competências segue a perspectiva de Le Boterf (ANECA, 2005), que as define como conhecimentos combinados e não fragmentados, bem como relacionados à ação profissional. As orientações ainda citam Isus (ANECA, 2005), que explica que as competências comportam um conjunto de conhecimentos, de procedimentos, de atitudes e de capacidades que são pessoais e se complementam entre si para que o profissional atue com eficiência frente às situações profissionais, devendo saber, saber fazer, saber estar, saber ser, saber aprender e fazer saber.

De acordo com as explicações do documento da ANECA, houve consenso entre os integrantes que elaboraram a proposta para partirem de delimitações conceituais mínimas e,

Práxis Educativa, Ponta Grossa, v. 12, n. 2, p. 657-681, maio/ago. 2017 Disponível em: <http://www.revistas2.uepg.br/index.php/praxiseducativa > 
assim, ficaram definidas as competências como um conjunto de conhecimentos, habilidades, atitudes desenvolvidas no desempenho da profissão, em que se aplica o ser, o saber e o saber fazer. Essa descrição serve para compreender o percurso que resultou na organização dos currículos de formação dos Educadores Sociais.

\section{Procedimento metodológico e organização dos dados retirados das ementas das disciplinas de Pedagogia Social}

Para compreensão quanto à concepção de Pedagogia Social desenvolvida na realidade espanhola, foi organizado um processo de coleta e análise de dados pautados na perspectiva da metodologia da Educação Comparada. Para que o objetivo fosse atingido, optou-se por uma análise específica e profunda das ementas da disciplina de Pedagogia Social que compõem o quadro de formação do curso de Graduação em Educação Social das universidades espanholas.

A opção pela utilização desse método de análise qualitativo surge das conversas com a Professora Glória Perez Serrano, a qual, por meio de seus escritos e também dos encontros presenciais semanais e rigorosos, auxiliou no processo de legitimação das categorias escolhidas para as análises propostas, conforme estão apresentadas no próximo capítulo com dados coletados e suas primeiras análises. É importante enfatizar que essas mesmas categorias também foram colocadas à prova em um debate junto a outros professores da área de Educação Social da Universidad Nacional de Educación a Distância, resultando em reelaborações que culminaram no resultado final.

Para Perez Serrano (2003, p. 329), a Análise de Conteúdo trata de analisar e estudar detalhadamente o conteúdo de uma comunicação seja escrita, oral ou visual. Para a autora, existe uma sequência a ser seguida para que o estudo proposto tenha validade científica:

1 - Definir o objetivo que se pretende conseguir.

2 - Definir o universo a ser estudado.

3 - Determinar as unidades de análises.

4 - Elaboração de hipóteses.

5 - Determinar as categorias significativas.

6 - Elaborar um guia objetivo.

7 - Quantificar e expressar matematicamente cada uma das categorias.

8 - Interpretação dos dados obtidos e elaboração de conclusões.

Durante as primeiras orientações, foi definido que o recorte a ser estudado seria a disciplina Pedagogia Social, que está inserida nos cursos de Graduação em Educação Social das universidades espanholas. Essa opção justifica-se por entender que a ementa que fundamenta a disciplina seja resultado do processo histórico, que incorpora os pressupostos teóricos e metodológicos desenvolvidos pela intelectualidade espanhola, inclusive nas aproximações com as vertentes alemã, francófona e anglo-saxã. Ela expressa, portanto, o estágio atual de desenvolvimento da Pedagogia Social na Espanha e constitui elemento-chave para compreender a essência da formação de Educadores Sociais no país.

De acordo com Perez Serrano (2003), o primeiro passo a ser seguido em uma análise de conteúdo é a definição do objetivo que se pretende conseguir. O objetivo dessa fase da pesquisa é conhecer a concepção de Pedagogia Social que norteia a formação do Educador Social na Espanha. O segundo passo, de acordo com a autora, é a definição do universo a ser estudado. Nesse caso particular, foram escolhidas dez universidades espanholas que ofertam a Graduação em Educação Social e que incluem, em seus planos de curso, a disciplina Pedagogia Social. São

Práxis Educativa, Ponta Grossa, v. 12, n. 2, p. 657-681, maio/ago. 2017 Disponível em: <http://www.revistas2.uepg.br/index.php/praxiseducativa > 
elas: Universidad Nacional de Educación a Distancia - UNED (Comunidad de Madrid); Universidad Autónoma de Barcelona - UAB (Cataluña); Universidad Castilla la Mancha - UCLM (Castilla La-Mancha); Universidad Santiago de Compostela - USC (Galicia); Universidad de Salamanca - USAL (Castilla y León); Universidad de Deusto - UD (País Vasco); Universidad de León - ULE (Castilla y León); Universidad de Valencia - UV (Comunidad Valenciana); Universidad de Las Palmas de Gran Canarias - ULPGC (Canarias); Universidad de Málaga UMA (Andaluzia)

O terceiro passo apontado pela pesquisadora é determinar as unidades de análise. Depois de selecionadas as universidades e do acesso aos programas dos Cursos de Graduação em Educação Social disponíveis na internet, foi possível acessar as ementas das disciplinas de Pedagogia Social vigentes no ano de 2012, para a organização das unidades de análise, que, depois, possibilitariam a estruturação e a definição de categorias e subcategorias. As unidades de análise que foram escolhidas para a realização do estudo foram os itens presentes nas ementas da disciplina que correspondem a: Objetivos, Competências, Conteúdos e Referências.

O quarto passo é a elaboração de hipóteses. A hipótese levantada com essa análise é referente a uma possível existência de uma coesão e um equilíbrio entre questões teóricas e práticas consideradas como parte da formação do Educador Social a partir da Disciplina de Pedagogia Social.

O quinto passo é determinar as categorias significativas, que, nesse caso, foram organizadas da seguinte maneira:

- Objetivos: Dentro dessa unidade de análise, nas ementas das disciplinas, aparecem diferentes itens que foram agrupados nas seguintes grandes categorias: Saber, Saber fazer, Saber ser. Cada grande categoria está dividida em categorias menores, que servem para organizar a análise de conteúdo proposta.

- Objetivos Saber: Origem e evolução da PS; Conceitos, Teorias e Fundamentos da PS; Paradigmas e Metodologias da PS; Aspectos profissionais e de intervenção em PS.

- Objetivos Saber fazer: Intervenção em PS; Formação do Educador Social; O trabalho do Educador Social.

- Objetivos Saber ser: Postura crítica do Educador Social; Resolução de problemas por parte do Educador Social; Responsabilidades do Educador Social.

- Competências: Estão subdivididas nas seguintes grandes categorias: Saber, Saber fazer, Saber ser.

As "categorias menores" estão organizadas da seguinte maneira:

- Competências Saber: Origem e evolução da PS; Conceitos, Teorias e Fundamentos da PS; Paradigmas e Metodologias da PS; Aspectos profissionais e de Intervenção em PS.

- Competências Saber faz̧er. Intervenção em PS; Formação do Educador Social; O trabalho do Educador Social.

- Competências Saber ser: Postura crítica do Educador Social; Resolução de problemas por parte do Educador Social; Responsabilidades do Educador Social.

Práxis Educativa, Ponta Grossa, v. 12, n. 2, p. 657-681, maio/ago. 2017 Disponível em: <http://www.revistas2.uepg.br/index.php/praxiseducativa> 
- Conteúdos: Estão divididos nas seguintes grandes categorias: Aspectos históricos; Aspectos conceituais; Intervenção em Educação Social; Profissionalização do Educador Social; Metodologia.

As “categorias menores" estão organizadas da seguinte maneira:

- Aspectos históricos: Origem e evolução da PS: perspectiva histórica e situação atual; Representantes da PS; Perspectiva histórica comparada da PS.

- Aspectos conceituais: Objeto de estudo da PS; PS como ciência; Diferentes paradigmas da PS; PS, interdisciplinaridade e conceitos afins; Dimensão política da PS.

- Intervenção em Educação Social: Paradigmas e modelos da intervenção em ES; Espaços de intervenção da ES.

- Profissionalização do Educador Social: Perfis do Educador Social; Profissionalização e deontologia.

- Metodologia: Investigação em ES; Projetos e Técnicas de intervenção em ES.

- A unidade de análise Referências foi subdividida nas seguintes subcategorias: Aspectos históricos e conceituais; Aspectos e âmbitos de intervenção socioeducativa; Aspectos profissionais; Aspectos políticos; Aspectos metodológicos e técnicas.

Essas descrições, juntamente às Tabelas que seguem, compõem a sexta fase da análise de conteúdo, que, de acordo com Perez Serrano (2003), é elaborar um guia objetivo.

A autora ainda coloca o sétimo e oitavo passos que finalizam a aplicação do método, que resulta na quantificação dos dados obtidos e na interpretação/elaboração de conclusões, respectivamente.

$\mathrm{Na}$ sequência, foram elaborados os gráficos a partir das informações contidas nas tabelas, com o intuito de quantificar e proporcionar as possíveis reflexões para atingir o objetivo proposto nessa parte do trabalho. É importante ressaltar que todas as unidades de análise, bem como as categorias maiores e menores, foram retiradas das próprias ementas da disciplina. Elas foram reorganizadas para dar visibilidade e acessar dados que surgem quando o método de análise de conteúdo é aplicado.

Outro ponto a ser enfatizado é que, nesta pesquisa, a proposta é analisar as ementas da Disciplina de Pedagogia Social que compõem a Grade Curricular do Curso de Graduação em Educação Social das dez universidades escolhidas. Em todo o curso, existem várias outras disciplinas que certamente abordam outras questões que não foram tratadas neste trabalho. Também é importante esclarecer que as análises a serem realizadas consideram apenas o texto apresentado nos documentos, pois não foi realizado outro aporte metodológico que permitisse aferir dados das práticas dos professores que trabalham com a disciplina de Pedagogia Social, nas referidas universidades. 
Quadros e gráficos com os dados retirados das ementas das disciplinas de Pedagogia Social

- Unidade de análise: Objetivos

Tabela 1 - Objetivos Saber

\begin{tabular}{l|c|c|c|c}
\hline & $\begin{array}{c}\text { Origem e } \\
\text { evolução da PS. }\end{array}$ & $\begin{array}{c}\text { Conceitos, teorias } \\
\text { e fundamentos da } \\
\text { PS. }\end{array}$ & $\begin{array}{c}\text { Paradigmas e } \\
\text { metodologias da } \\
\text { PS. }\end{array}$ & $\begin{array}{c}\text { Aspectos } \\
\text { profissionais e de } \\
\text { intervenção em } \\
\text { PS. }\end{array}$ \\
\hline 1-UNED & 1 & 1 & 1 & 1 \\
\hline 2-UAB & 1 & 1 & 1 & 2 \\
\hline 3-UCLM & & 4 & & \\
\hline 4-USC & & 2 & & \\
\hline 5- USAL & 1 & 2 & & \\
\hline 6-UD & 1 & 1 & & \\
\hline 7-ULE & 3 & 2 & & \\
\hline 8-UV & 1 & 1 & & \\
\hline 9-ULPGC & $\mathbf{6}$ & 1 & & \\
\hline 10-UMA & & $\mathbf{9}$ & & \\
\hline Total 10 & & & & \\
\hline
\end{tabular}

Fonte: Ribas Machado (2014, p. 109).

Gráfico 1 - Objetivos Saber

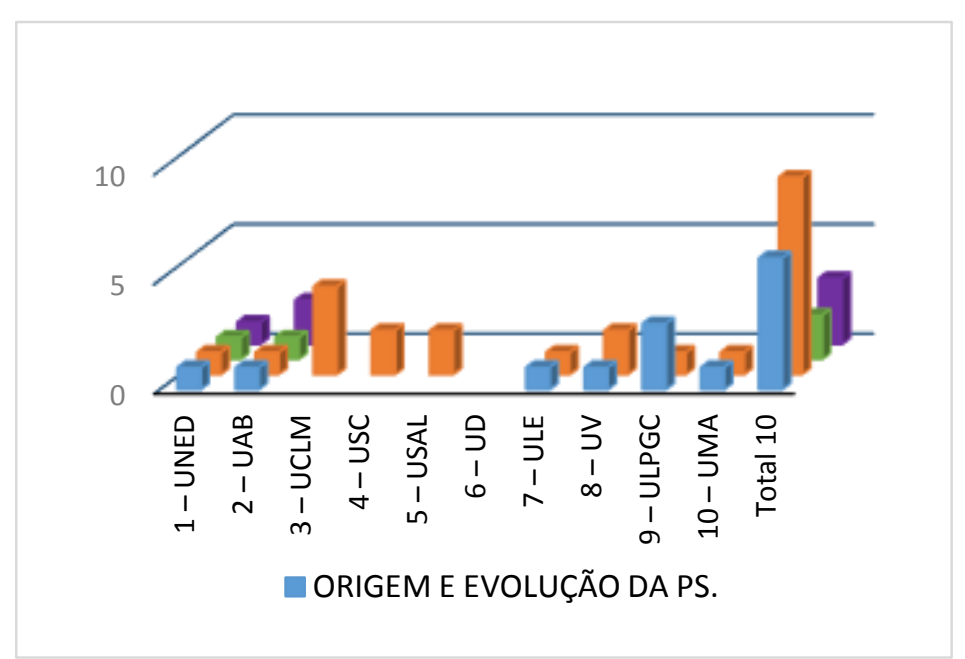

Fonte: Ribas Machado (2014, p. 110).

Práxis Educativa, Ponta Grossa, v. 12, n. 2, p. 657-681, maio/ago. 2017 Disponível em: <http://www.revistas2.uepg.br/index.php/praxiseducativa > 
Tabela 2 - Objetivos Saber fazer

\begin{tabular}{|c|c|c|c|}
\hline & Intervenção em PS. & $\begin{array}{c}\text { Formação do Educador } \\
\text { Social }\end{array}$ & $\begin{array}{c}\text { O trabalho do Educador } \\
\text { Social }\end{array}$ \\
\hline 1 - UNED & 1 & & \\
\hline $2-\mathrm{UAB}$ & 1 & & \\
\hline \multicolumn{4}{|l|}{ 3- UCLM } \\
\hline 4 - USC & 1 & 1 & 1 \\
\hline 5 - USAL & 2 & & \\
\hline 6-UD & & 2 & \\
\hline 7 - ULE & & & 1 \\
\hline $8-U V$ & 2 & & 2 \\
\hline 9- ULPGC & 3 & & 1 \\
\hline 10 - UMA & 1 & & 3 \\
\hline Total 10 & 7 & 2 & 5 \\
\hline
\end{tabular}

Fonte: Ribas Machado (2014, p. 110).

Gráfico 2 - Objetivos Saber fazer

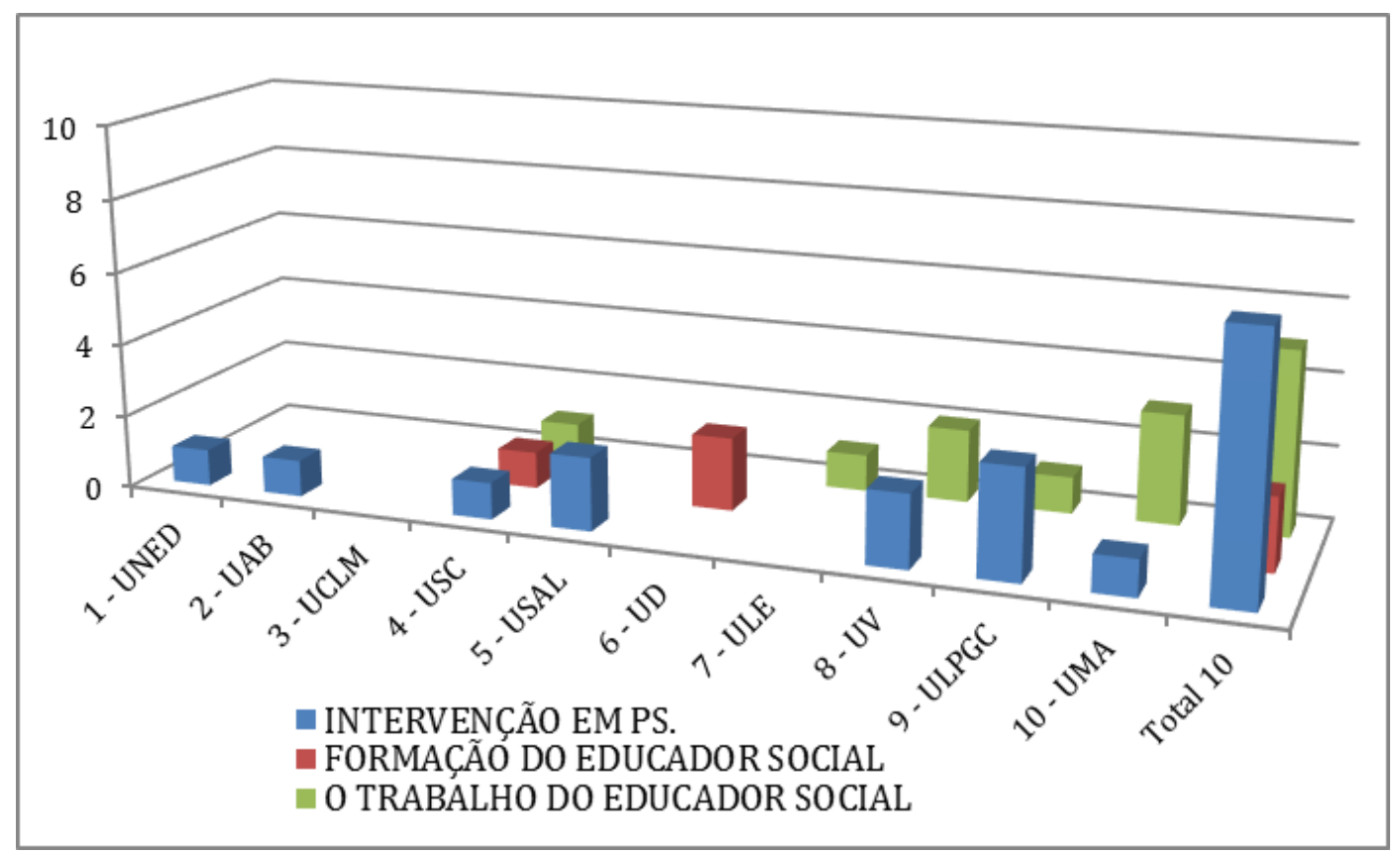

Fonte: Ribas Machado (2014, p. 111). 
Tabela 3 - Objetivos Saber ser

\begin{tabular}{l|c|c|c}
\hline 1-UNED & $\begin{array}{c}\text { Postura crítica do } \\
\text { Educador Social }\end{array}$ & $\begin{array}{c}\text { Resolução de problemas por } \\
\text { parte do Educador Social }\end{array}$ & $\begin{array}{c}\text { Responsabilidades do } \\
\text { Educador Social }\end{array}$ \\
\hline $\mathbf{2}$ - UAB & 1 & & \\
\hline - UCLM & 1 & & \\
\hline - - USC & & 1 & 1 \\
\hline - USAL & & 1 & 1 \\
\hline 6-UD & 1 & 1 & \\
\hline 7- ULE & & & 2 \\
\hline 8- UV & 1 & 3 & \\
\hline 9- ULPGC & 4 & & \\
\hline 10-UMA & & & \\
\hline Tota1 10 & & & \\
\hline
\end{tabular}

Fonte: Ribas Machado (2014, p. 111).

Gráfico 3 - Objetivos Saber ser

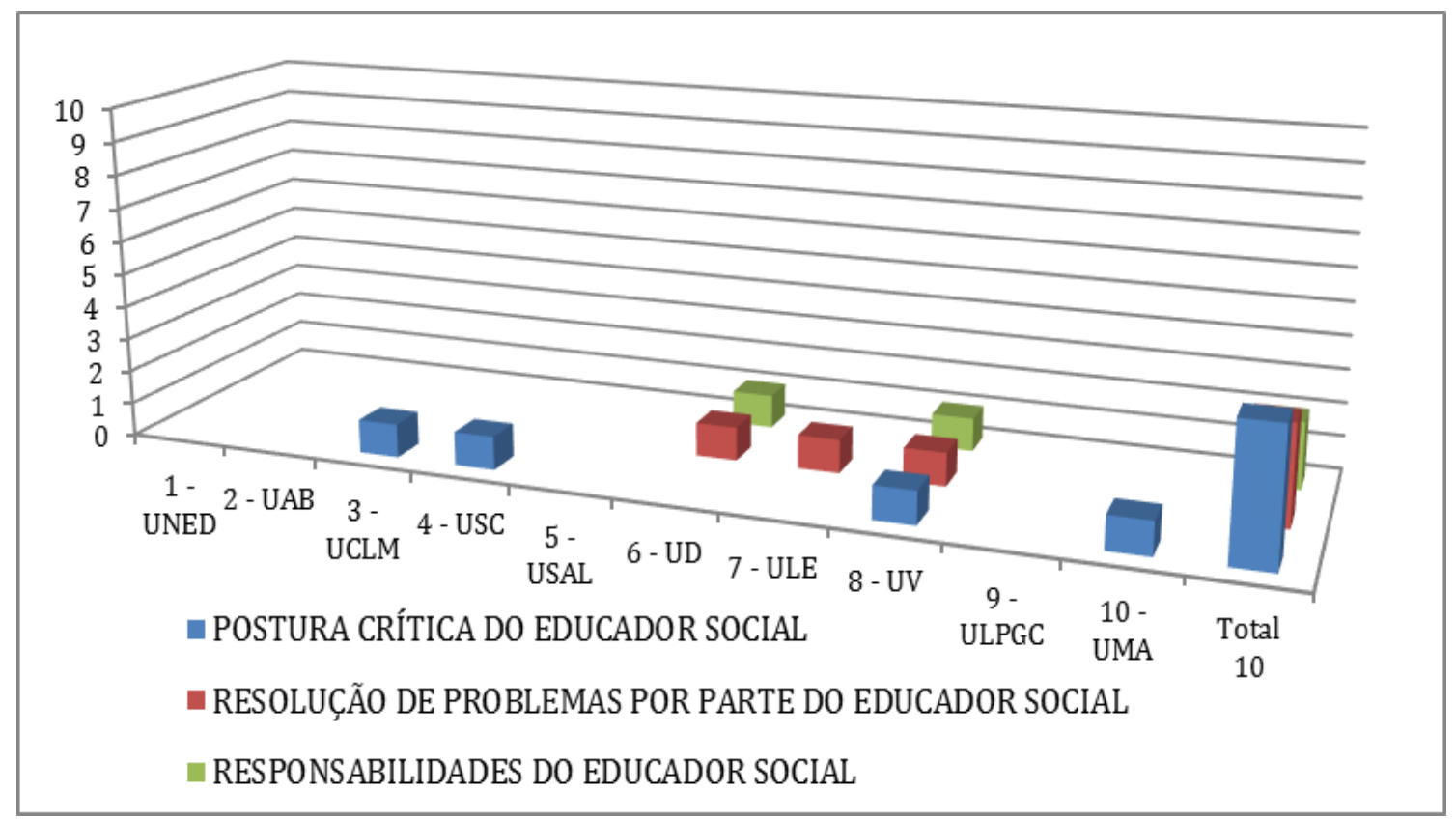

Fonte: Ribas Machado (2014, p. 112). 
- Unidade de análise: Competências

Tabela 4 - Competências Saber

\begin{tabular}{|c|c|c|c|c|}
\hline & $\begin{array}{c}\text { Origem e } \\
\text { evolução da PS. }\end{array}$ & $\begin{array}{l}\text { Conceitos, teorias e } \\
\text { fundamentos da } \\
\text { PS. }\end{array}$ & $\begin{array}{c}\text { Paradigmas e } \\
\text { metodologias da } \\
\text { PS. }\end{array}$ & $\begin{array}{c}\text { Aspectos } \\
\text { profissionais e de } \\
\text { intervenção em PS. }\end{array}$ \\
\hline 1 - UNED & & 2 & 1 & 2 \\
\hline $2-\mathrm{UAB}$ & & 1 & 1 & 1 \\
\hline 3- UCLM & 2 & 1 & & 1 \\
\hline 4 - USC & 1 & 2 & 1 & 1 \\
\hline 5 - USAL & 2 & 1 & & \\
\hline 6-UD & 2 & 1 & & \\
\hline \multicolumn{5}{|l|}{7 - ULE } \\
\hline \multicolumn{5}{|l|}{$8-U V$} \\
\hline 9- ULPGC & 1 & 2 & 3 & \\
\hline 10 - UMA & 1 & & & 1 \\
\hline Total 10 & 6 & 7 & 4 & 5 \\
\hline
\end{tabular}

Fonte: Ribas Machado (2014, p. 112).

Gráfico 4 - Competências Saber

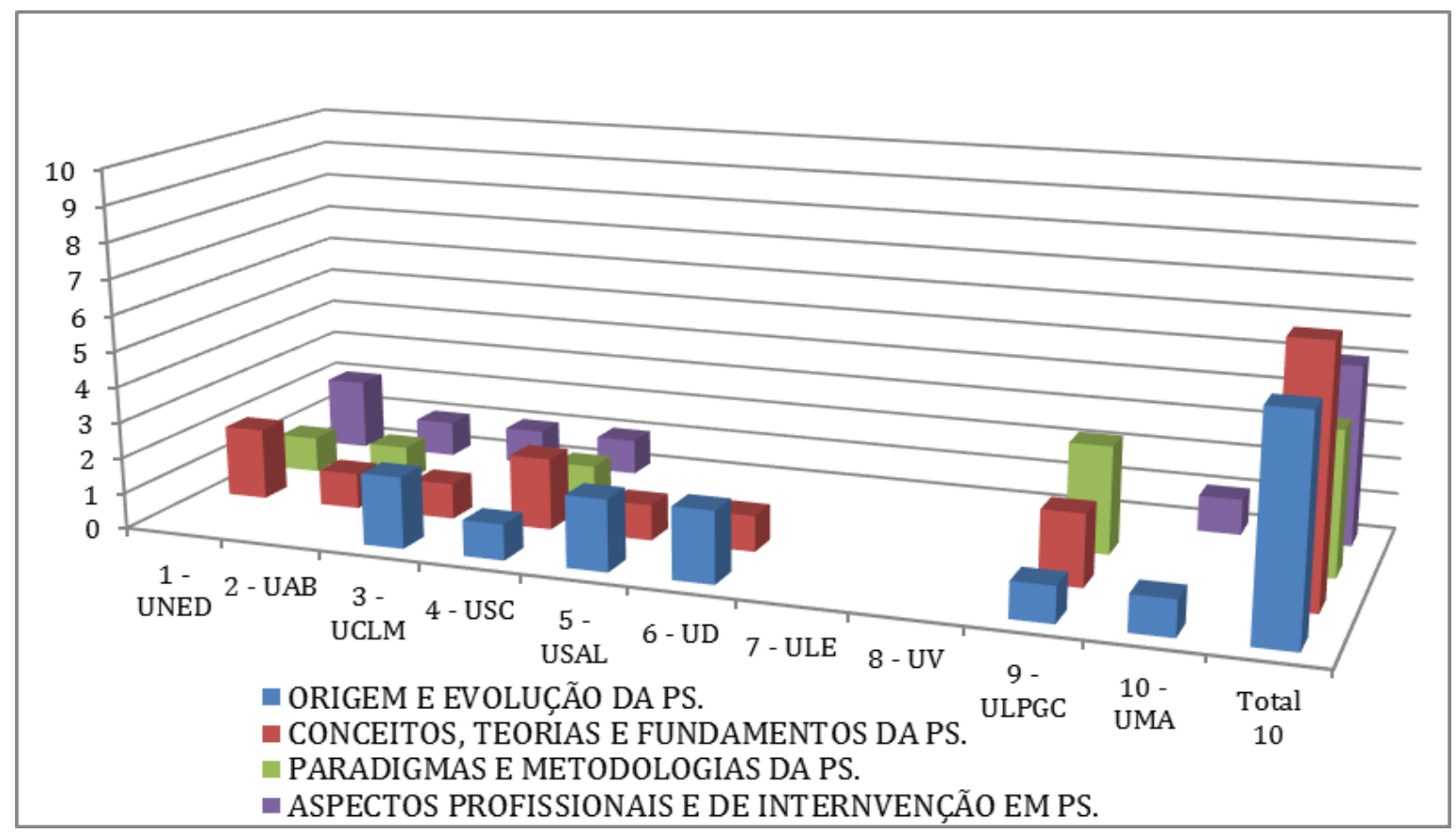

Fonte: Ribas Machado (2014, p. 113). 
Tabela 5 - Competências Saber fazer

\begin{tabular}{|c|c|c|c|}
\hline & Intervenção em PS. & $\begin{array}{c}\text { Formação do Educador } \\
\text { Social }\end{array}$ & $\begin{array}{c}\text { O trabalho do Educador } \\
\text { Social }\end{array}$ \\
\hline \multicolumn{4}{|l|}{1 - UNED } \\
\hline $2-\mathrm{UAB}$ & & & 2 \\
\hline \multicolumn{4}{|l|}{ 3- UCLM } \\
\hline $4-$ USC & & 1 & 2 \\
\hline 5 - USAL & 2 & & \\
\hline 6-UD & 1 & & 1 \\
\hline 7 - ULE & & 2 & \\
\hline $8-U V$ & & 3 & \\
\hline 9- ULPGC & 1 & & \\
\hline 10 - UMA & & & 3 \\
\hline Total 10 & 3 & 3 & 4 \\
\hline
\end{tabular}

Fonte: Ribas Machado (2014, p. 113).

Gráfico 5 - Competências Saber fazer

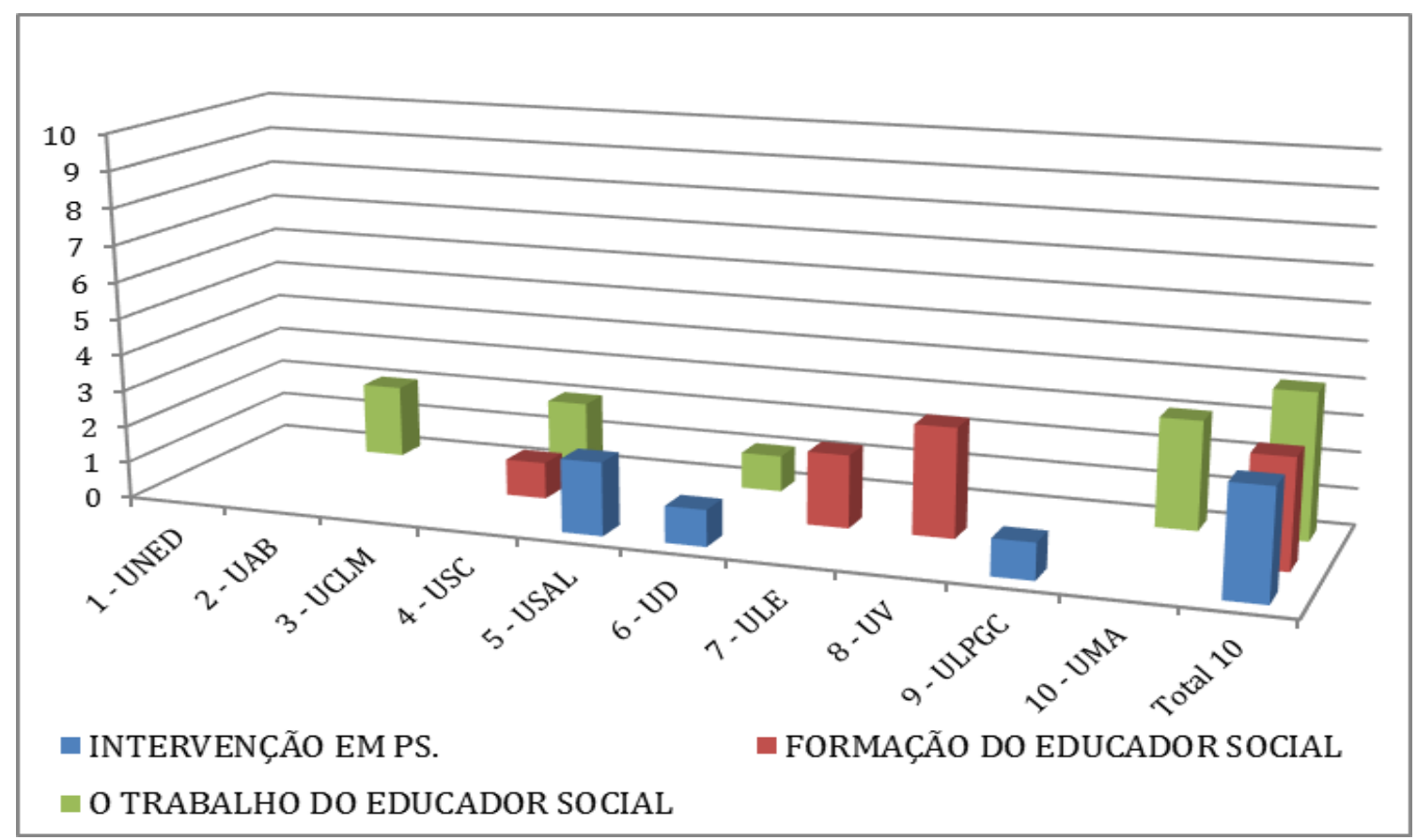

Fonte: Ribas Machado (2014, p. 114). 
Tabela 6 - Competências Saber ser

\begin{tabular}{l|c|c|c}
\hline & $\begin{array}{c}\text { Postura crítica do } \\
\text { Educador Social }\end{array}$ & $\begin{array}{c}\text { Resolução de problemas } \\
\text { por parte do Educador } \\
\text { Social }\end{array}$ & $\begin{array}{c}\text { Responsabilidades do } \\
\text { Educador Social }\end{array}$ \\
\hline 1-UNED & 1 & 3 & 3 \\
\hline 2-UAB & 1 & & 1 \\
\hline 3-UCLM & 1 & & 2 \\
\hline 4-USC & & & 2 \\
\hline 5-USAL & 1 & 2 & \\
\hline 6-UD & & 2 & \\
\hline 7-ULE & & & 6 \\
\hline 8-UV & & 3 & \\
\hline 9-ULPGC & 4 & & \\
\hline 10-UMA & & & \\
\hline Total 10 & & & \\
\hline
\end{tabular}

Fonte: Ribas Machado (2014, p. 114).

Gráfico 6 - Competências Saber ser

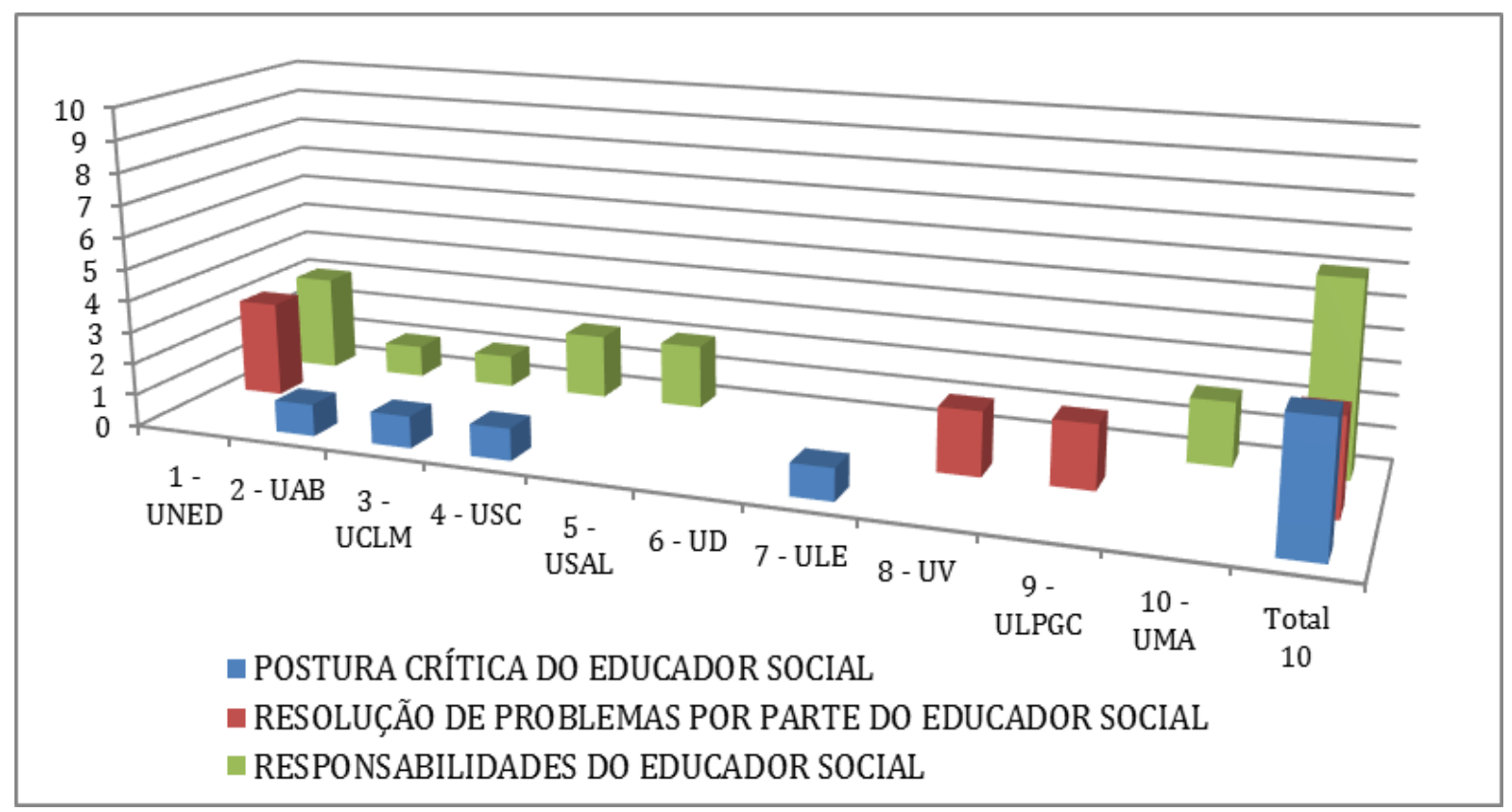

Fonte: Ribas Machado (2014, p. 115).

Práxis Educativa, Ponta Grossa, v. 12, n. 2, p. 657-681, maio/ago. 2017 Disponível em: < http://www.revistas2.uepg.br/index.php/praxiseducativa> 


\section{Resumo dos dados quantificados: unidades de análise Objetivos e Competências}

Aspectos teóricos:

- Conceitos, fundamentos e teorias da Pedagogia Social - 25 vezes.

- Origem e evolução da Pedagogia Social - 17 vezes.

- Paradigmas e metodologias da Pedagogia Social - 8 vezes.

TOTAL: 50.

Aspectos práticos:

- Aspectos profissionais e de intervenção em Pedagogia Social - 5 vezes.

- Intervenção em Pedagogia Social - 15 vezes.

- Formação do Educador Social - 9 vezes.

- O trabalho do Educador Social - 16 vezes.

- Postura crítica do Educador Social - 8 vezes.

- Resolução de problemas por parte do Educador Social - 10 vezes.

- Responsabilidades do Educador Social - 13 vezes.

TOTAL: 76.

- Unidade de análise: Conteúdos

Tabela 7 - Aspectos históricos

\begin{tabular}{|c|c|c|c|}
\hline & $\begin{array}{c}\text { Origem e evolução da PS: } \\
\text { perspectiva histórica e } \\
\text { situação atual }\end{array}$ & Representantes da PS & $\begin{array}{l}\text { Perspectiva histórica } \\
\text { comparada da PS }\end{array}$ \\
\hline 1 - UNED & 1 & & \\
\hline $2-\mathrm{UAB}$ & 2 & 1 & \\
\hline 3-UCLM & 4 & 4 & 2 \\
\hline 4 - USC & & & 1 \\
\hline \multicolumn{4}{|l|}{5 - USAL } \\
\hline 6-UD & 1 & & \\
\hline 7 - ULE & 2 & 1 & \\
\hline \multicolumn{4}{|l|}{ 8-UV } \\
\hline 9-ULPGC & & 1 & \\
\hline 10 - UMA & 1 & & \\
\hline Total 10 & 6 & 4 & 2 \\
\hline
\end{tabular}

Fonte: Ribas Machado (2014, p. 117).

Práxis Educativa, Ponta Grossa, v. 12, n. 2, p. 657-681, maio/ago. 2017 Disponível em: <http://www.revistas2.uepg.br/index.php/praxiseducativa > 
Gráfico 7 - Aspectos históricos

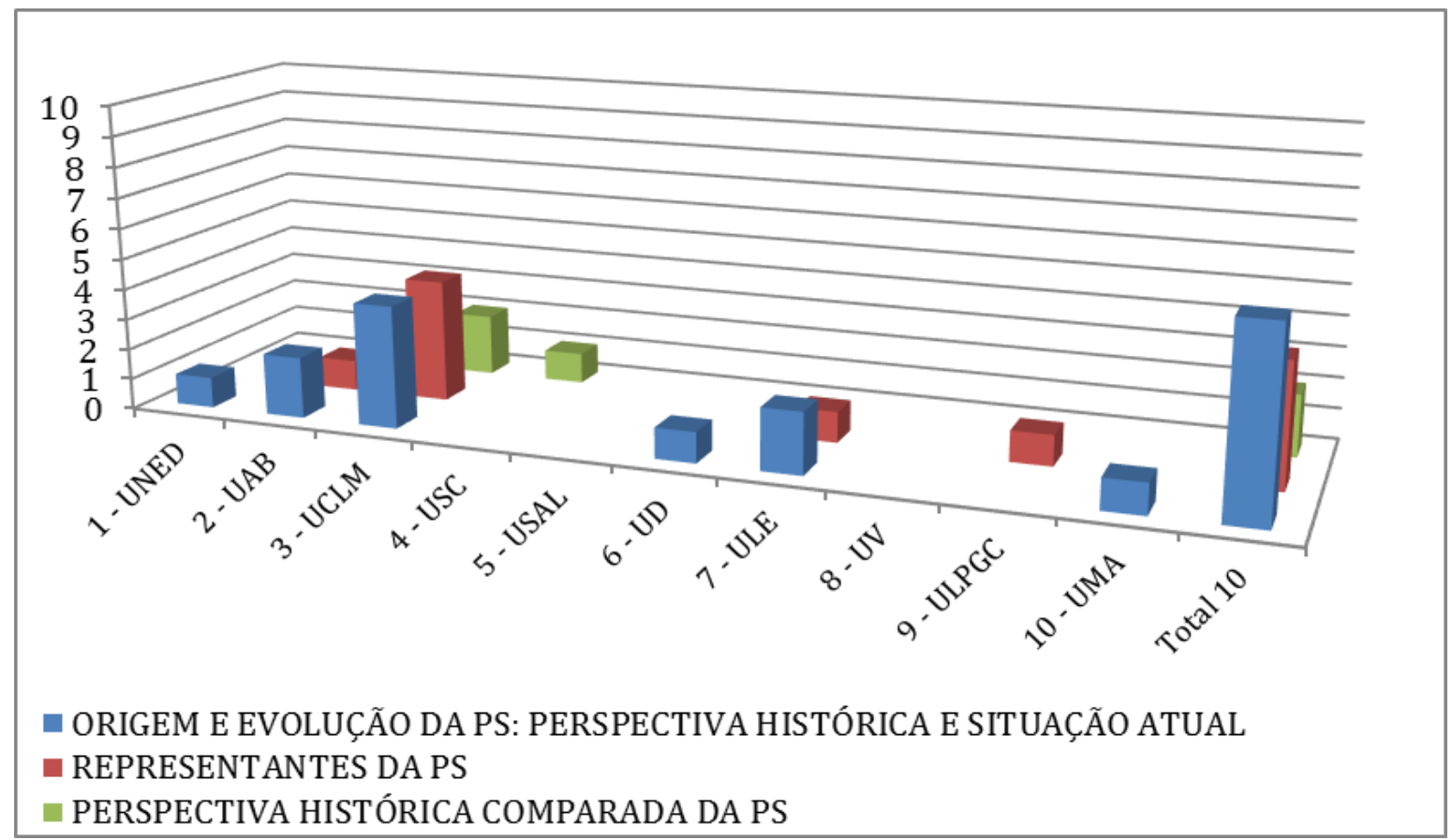

Fonte: Ribas Machado (2014, p. 117)

Tabela 8 - Aspectos conceituais

\begin{tabular}{l|c|c|c|c|c}
\hline & $\begin{array}{c}\text { Objeto de } \\
\text { estudo da } \\
\text { PS }\end{array}$ & $\begin{array}{c}\text { PS como } \\
\text { Ciência }\end{array}$ & $\begin{array}{c}\text { Diferentes } \\
\text { paradigmas } \\
\text { da PS }\end{array}$ & $\begin{array}{c}\text { PS, interdisciplinaridade e } \\
\text { conceitos afins }\end{array}$ & $\begin{array}{c}\text { Dimensão } \\
\text { política em } \\
\text { PS }\end{array}$ \\
\hline 1-UNED & 2 & 1 & 1 & & 1 \\
\hline 2-UAB & & & 5 & 1 & 1 \\
\hline 3-UCLM & 3 & 3 & 1 & & 1 \\
\hline 4-USC & 1 & 1 & 1 & 2 & \\
\hline 5-USAL & 1 & 1 & & 2 & 1 \\
\hline 6-UD & & & & 1 & 1 \\
\hline 7-ULE & 1 & & & & \\
\hline 8-UV & & & 2 & & 5 \\
\hline 9-ULPGC & 1 & & & $\mathbf{6}$ & \\
\hline 10-UMA & 2 & & & & \\
\hline Total 10 & 7 & 4 & $\mathbf{5}$ & & \\
\hline
\end{tabular}

Fonte: Ribas Machado (2014, p. 118) 
Gráfico 8 - Aspectos conceituais

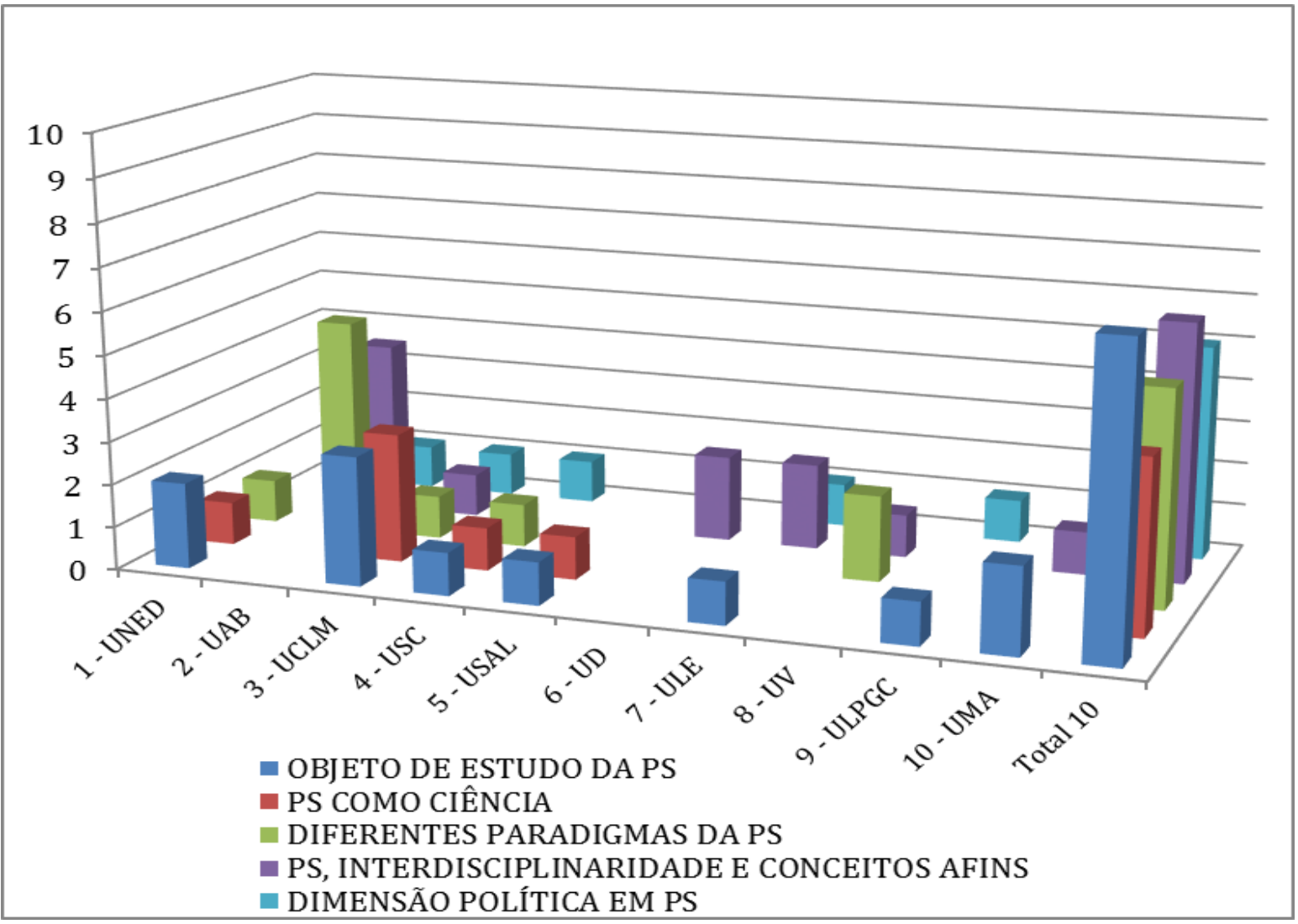

Fonte: Ribas Machado (2014, p. 118).

Tabela 9 - Intervenção em Educação Social

\begin{tabular}{|c|c|c|}
\hline & $\begin{array}{c}\text { Paradigmas e modelos da intervenção } \\
\text { em ES }\end{array}$ & Espaços de intervenção da ES \\
\hline 1 - UNED & 1 & 1 \\
\hline $2-\mathrm{UAB}$ & 5 & 2 \\
\hline \multicolumn{3}{|l|}{ 3-UCLM } \\
\hline $4-$ USC & & 2 \\
\hline 5- USAL & & 1 \\
\hline 6-UD & 1 & 1 \\
\hline 7 - ULE & 3 & 1 \\
\hline $8-U V$ & & 1 \\
\hline 9- ULPGC & 1 & 1 \\
\hline 10 - UMA & & 1 \\
\hline Total 10 & 5 & 9 \\
\hline
\end{tabular}

Fonte: Ribas Machado (2014, p. 119). 
Gráfico 9 - Intervenção em Educação Social

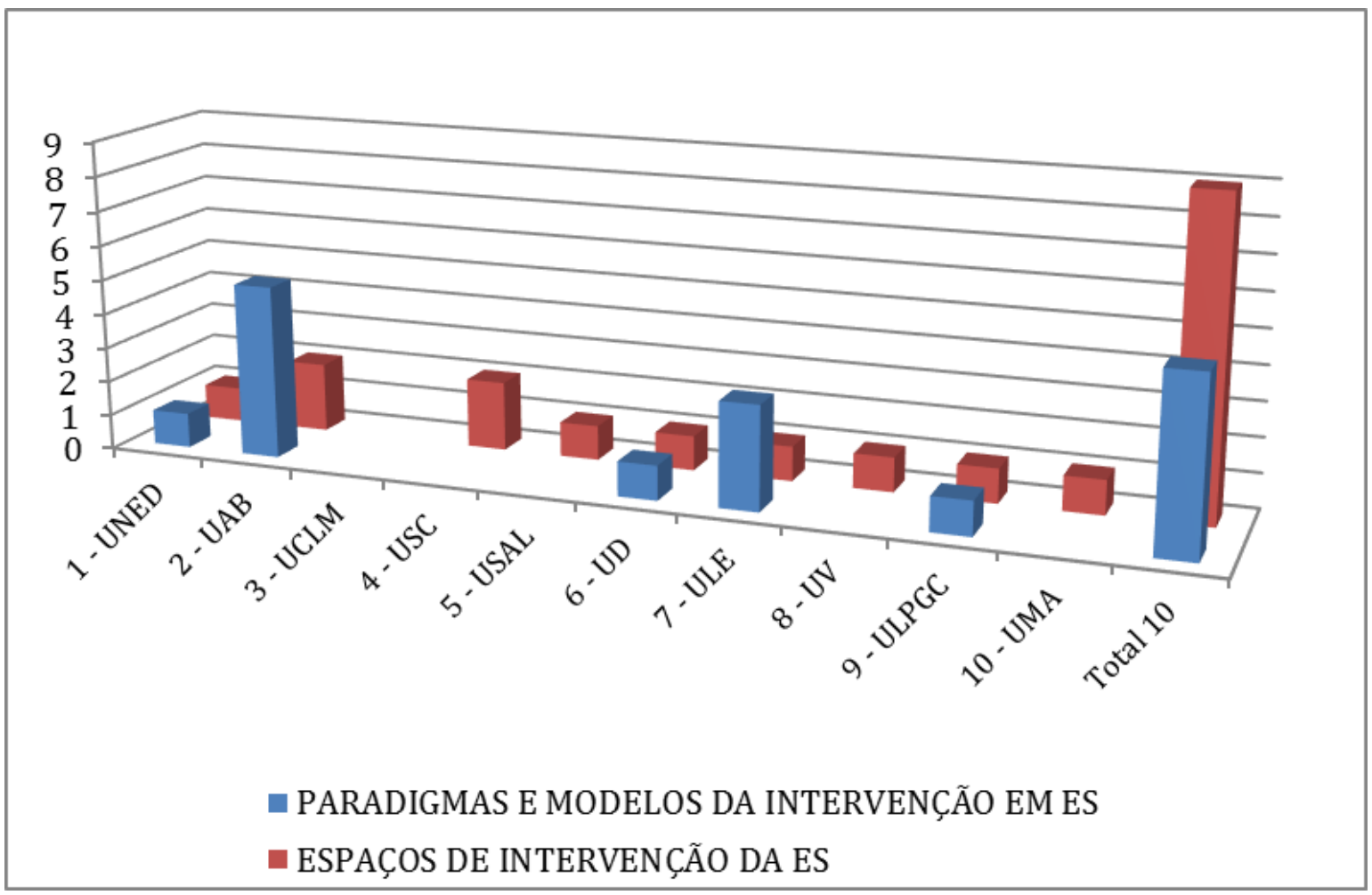

Fonte: Ribas Machado (2014, p. 119).

Tabela 10 - Profissionalização do Educador Social

\begin{tabular}{|c|c|c|}
\hline & Perfis do Educador Social & Profissionalização e deontologia \\
\hline 1 - UNED & & 1 \\
\hline $2-\mathbf{U A B}$ & 3 & \\
\hline 3-UCLM & 1 & 1 \\
\hline $4-\mathrm{USC}$ & & 1 \\
\hline 5 - USAL & 1 & 1 \\
\hline 6-UD & 1 & \\
\hline 7 - ULE & 1 & \\
\hline $8-\mathrm{UV}$ & 1 & \\
\hline 9-ULPGC & 1 & \\
\hline 10 - UMA & 1 & 2 \\
\hline Total 10 & 8 & 5 \\
\hline
\end{tabular}

Fonte: Ribas Machado (2014, p. 120). 
Gráfico 10 - Profissionalização do Educador Social

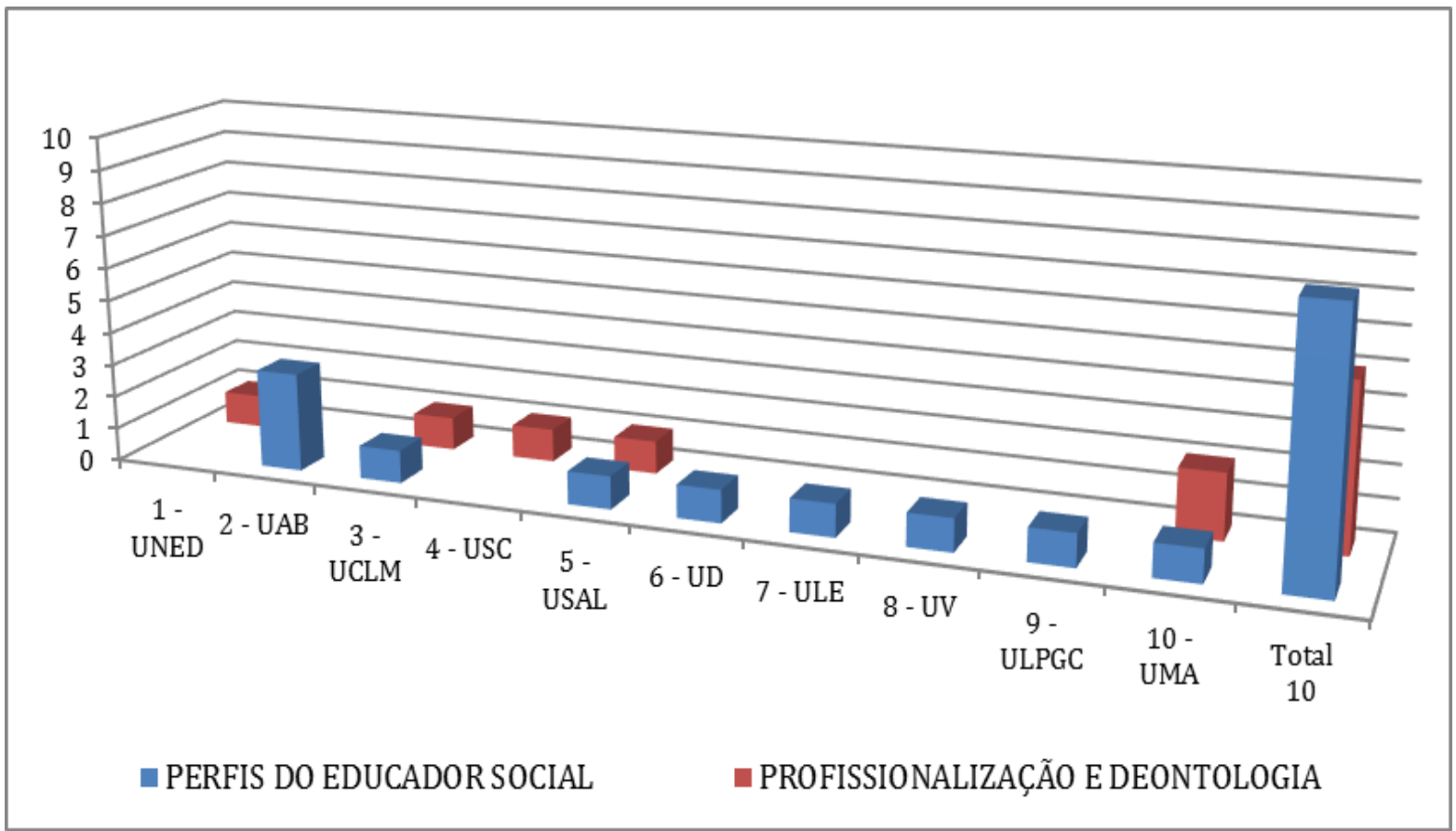

Fonte: Ribas Machado (2014, p. 120).

Tabela 11 - Metodologia

\begin{tabular}{|c|c|c|}
\hline & Investigação em ES & Projetos e técnicas de intervenção em ES \\
\hline 1 - UNED & & 1 \\
\hline \multicolumn{3}{|l|}{$2-\mathbf{U A B}$} \\
\hline 3-UCLM & 1 & \\
\hline \multicolumn{3}{|l|}{$4-$ USC } \\
\hline \multicolumn{3}{|l|}{5 - USAL } \\
\hline 6-UD & 1 & \\
\hline 7 - ULE & & 1 \\
\hline $8-\mathrm{UV}$ & & 1 \\
\hline \multicolumn{3}{|l|}{ 9-ULPGC } \\
\hline 10 - UMA & & 1 \\
\hline Total 10 & 2 & 4 \\
\hline
\end{tabular}

Fonte: Ribas Machado (2014, p. 121). 
Gráfico 11 - Metodologia

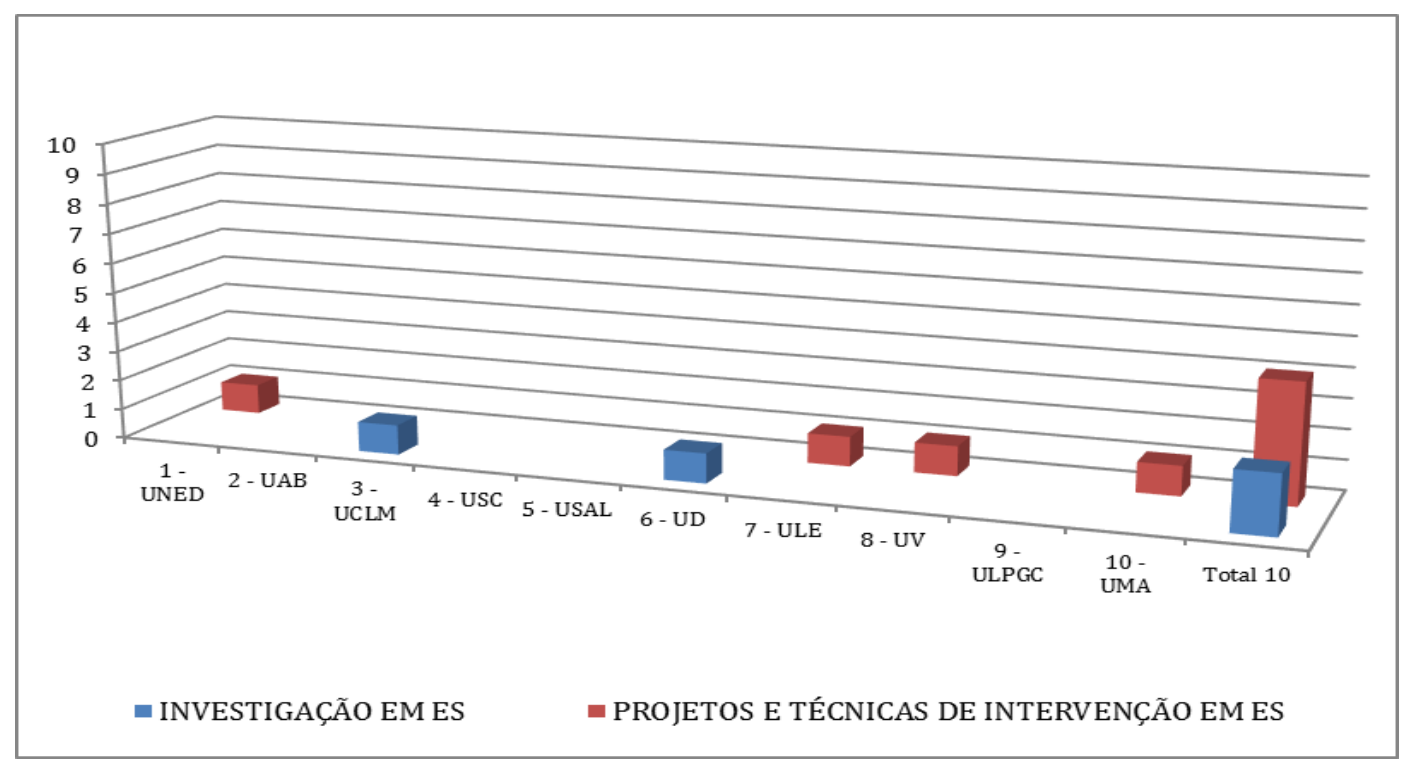

Fonte: Ribas Machado (2014, p. 121).

\section{Resumo dos dados quantificados: unidade de análise Conteúdos}

Aspectos teóricos

- Origem e evolução da Pedagogia Social: perspectiva histórica e atual - 11 vezes.

- Representantes da Pedagogia Social - 7 vezes.

- Perspectiva histórica comparada da Pedagogia Social - 3 vezes.

- Objeto de estudo da Pedagogia Social - 11 vezes.

- Pedagogia Social como Ciência - 6 vezes.

- Diferentes paradigmas da Pedagogia Social - 10 vezes.

- Pedagogia Social, interdisciplinaridade e conceitos afins - 11 vezes.

- Dimensão política da Pedagogia Social - 5 vezes.

- Paradigmas e modelos da intervenção em Educação Social - 11 vezes.

- Investigação em Educação Social - 2 vezes.

TOTAL: 77.

Aspectos práticos

- Espaços de intervenção da Educação Social - 11 vezes.

- Perfis do Educador Social - 10 vezes. 
A concepção de Pedagogia Social na formação dos Educadores Sociais na Espanha

- Profissionalização e deontologia - 6 vezes.

- Projetos e técnicas de intervenção em Educação Social - 4 vezes.

TOTAL: 31.

- Unidade de análise: Referências

Tabela 12 - Referências

\begin{tabular}{|c|c|c|c|c|c|}
\hline & $\begin{array}{l}\text { Aspectos } \\
\text { históricos- } \\
\text { conceituais }\end{array}$ & $\begin{array}{c}\text { Aspectos e } \\
\text { âmbitos de } \\
\text { intervenção } \\
\text { socioeducativa }\end{array}$ & $\begin{array}{c}\text { Aspectos } \\
\text { profissionais }\end{array}$ & $\begin{array}{l}\text { Aspectos } \\
\text { políticos }\end{array}$ & $\begin{array}{c}\text { Aspectos } \\
\text { metodológicos e de } \\
\text { técnicas }\end{array}$ \\
\hline 1 - UNED & 5 & 14 & 1 & & 1 \\
\hline $2-\mathrm{UAB}$ & 15 & 11 & 4 & 1 & 10 \\
\hline 3- UCLM & 5 & 2 & 2 & & \\
\hline $4-\mathrm{USC}$ & 7 & 4 & 5 & 2 & 1 \\
\hline 5 - USAL & 8 & 4 & 6 & & 2 \\
\hline 6-UD & 21 & 5 & 7 & 2 & 1 \\
\hline 7 - ULE & 5 & 1 & & & 3 \\
\hline 8-UV & 13 & 6 & & 9 & \\
\hline 9-ULPGC & 19 & 17 & 2 & 2 & 3 \\
\hline 10 - UMA & 19 & & 2 & & 1 \\
\hline Total 10 & 10 & 9 & 8 & 5 & 8 \\
\hline
\end{tabular}

Fonte: Ribas Machado (2014, p. 123).

Gráfico 12 - Referências

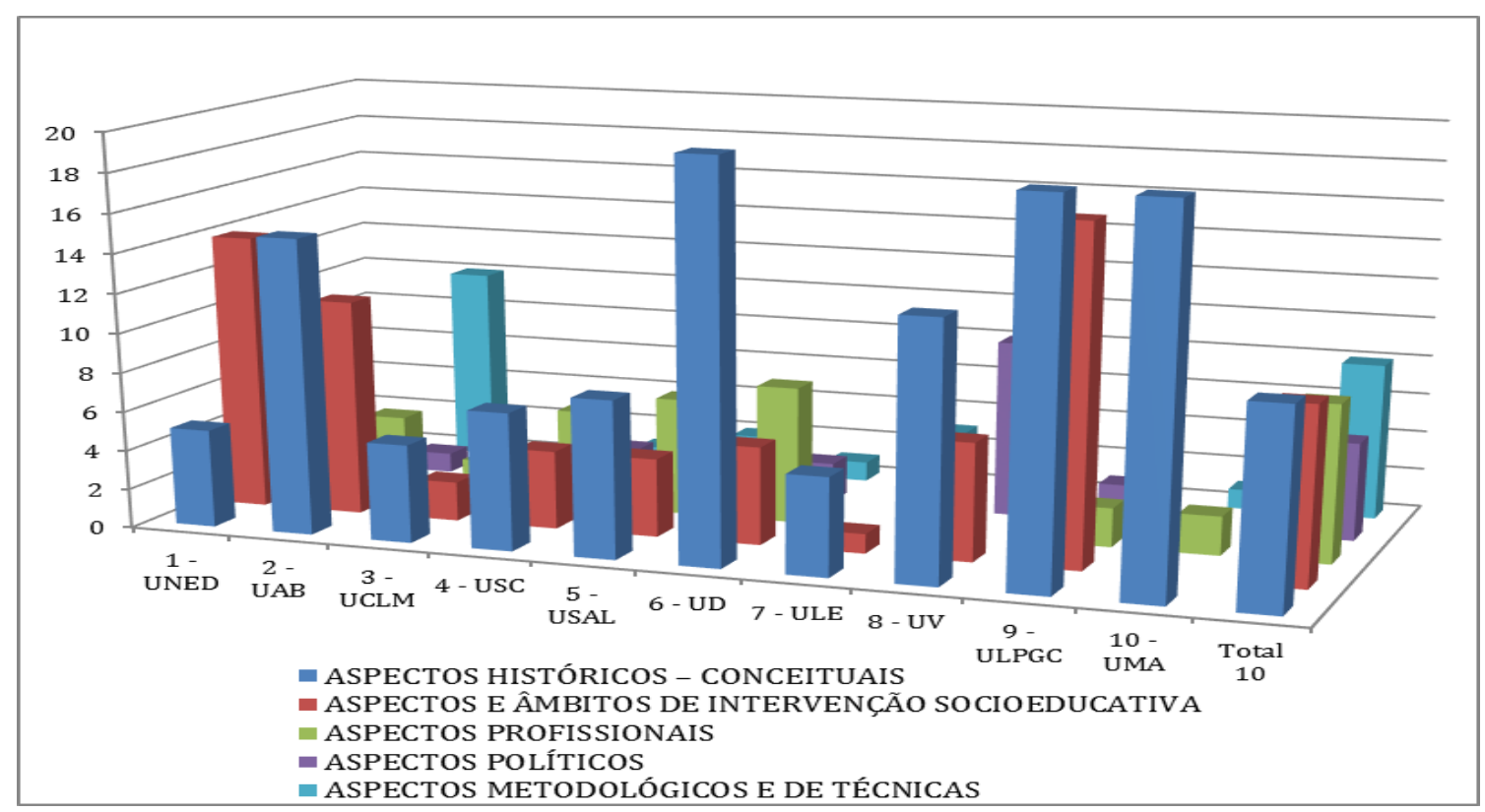

Fonte: Ribas Machado (2014).

Práxis Educativa, Ponta Grossa, v. 12, n. 2, p. 657-681, maio/ago. 2017 Disponível em: < http://www.revistas2.uepg.br/index.php/praxiseducativa $>$ 


\section{Resumo dos dados quantificados: unidades de análise Objetivos e Competências}

Aspectos teóricos

- Aspectos históricos - conceituais: 117 obras.

- Aspectos políticos: 16 obras.

TOTAL: 133.

Aspectos práticos

- Aspectos e âmbitos de intervenção socioeducativa: 64 obras.

- Aspectos profissionais: 29 obras.

- Aspectos metodológicos e de técnicas: 22 obras.

TOTAL: 115.

\section{Apontamentos sobre a concepção de Pedagogia Social na formação dos educadores sociais espanhóis}

De acordo com dados do Ministerio de Educación, Cultura y Deporte, em 2014, existiam 44 universidades que ofertavam o Curso de Graduação em Educação Social no país. Como informação também merece destaque o Consejo General de Colegios Oficiales de Colegios de Educadoras y Educadores Sociales, uma corporação de direito público, integrada por representantes de todas as associações de Educadoras e Educadores Sociais existentes na Espanha, sendo o seu representante coletivo em âmbito nacional e internacional. O número significativo de instituições que ofertam a formação profissional e de organizações que representam o Educador Social justifica o interesse em realizar o estudo detalhado a respeito da concepção de Pedagogia Social presente nessa formação.

O que se torna evidente com os estudos e os dados levantados nas ementas é o grande esforço dos pesquisadores da área em construí-la como uma disciplina teórico-prática, ou melhor, prático-teórica, ratificando todo o processo de construção de uma definição científica para a Pedagogia Social. E esse é o ponto principal que acabou chamando a atenção nas análises realizadas, devido ao rumo que o processo de coleta, organização e interpretação dos dados levou.

Durante o processo inicial de leitura das ementas e organização das informações, a primeira impressão era que o enfoque dado à disciplina de Pedagogia Social era predominantemente voltado à prática na formação do futuro profissional. Com a categorização das unidades de análise e aprofundamento das leituras e interpretação dos dados, ficou evidente que o que se preanunciava como uma disciplina com orientações para a prática, na realidade está orientada para os estudos teóricos, conforme demonstra o Quadro resumo a seguir. 
Quadro 1 - Elementos das ementas da disciplina de Pedagogia Social

\begin{tabular}{|c|c|c|}
\hline Objetivos e Competências & Conteúdos & Referências \\
\hline Elementos práticos 76 & Elementos teóricos 77 & Elementos teóricos 133 \\
Elementos teóricos 50 & Elementos práticos 31 & Elementos práticos 115 \\
\hline
\end{tabular}

Fonte: Ribas Machado (2014).

Essa primeira impressão foi forjada a partir da leitura e da comparação dos objetivos e das competências presentes nas ementas, possivelmente denotando uma intenção, um discurso ou uma meta a ser alcançada no processo de formação dos futuros profissionais, com vistas a melhor qualificação do trabalho do Educador Social nos diferentes âmbitos de intervenção da Educação Social. No decorrer da pesquisa, com o desmembramento e os reagrupamentos das informações para organizar as unidades de análise, verificou-se uma assimetria entre o que se propunha nos objetivos e nas competências com o que sugerem os conteúdos e as referências bibliográficas adotadas para o desenvolvimento da disciplina.

Pode parecer inusitado e até inadequado pretender deduzir a formação de determinado profissional a partir de uma única disciplina, situada em um Plano de Estudos de quatro anos de duração, e que oferece cerca de 30 disciplinas. Entretanto, não é demasiado recordar que o objetivo dessa parte da pesquisa de campo situada na Espanha teve por objetivo único e exclusivamente verificar a concepção de Pedagogia Social na formação dos Educadores Sociais.

O espanhol Sáez Carreras, catedrático de Pedagogía Social da Universidad de Murcia, também se questiona sobre a identidade da Pedagogia Social:

[Pedagogia Social] é ou não é uma ciência? E sé é mesmo, qual é a classificação dessa ciência? Qual ou quais são seus objetos de estudo? E seus métodos específicos de trabalho e de investigação? Quais funções cumprem no âmbito do saber? Qual é o tipo deste saber? É um saber para formar ou/e também para profissionalizar? Quais relações possuem este conhecimento teórico com a prática profissional? (SÁEZ CARRERAS, 1993, p. 40).

A diferença expressa entre o que se propõe como objetivos e competências, a partir do viés prático, mas com conteúdos essencialmente teóricos, talvez expresse diferentes preocupações dos pesquisadores que foram autores das ementas, mas que expõem a difícil tarefa de articular ou conectar as questões teóricas com as práticas, dentro da perspectiva da práxis. Esse é um reflexo que pode ser resultado de um processo histórico da área, articulado a outros elementos, conforme descrito a seguir.

A primeira observação é a respeito de uma interferência externa, por assim dizer, que busca a padronização na formação dos profissionais na Europa. Trata-se, mais especificamente, da estruturação das ementas das disciplinas dos cursos de Graduação de acordo com a lógica das competências, em consonância com as orientações supranacionais advindas do Processo de Bolonha que, por sua vez, incorporou orientações do Projeto Tuning, conforme já foi descrito anteriormente e que subsidia o documento produzido pela ANECA. Essa reflexão crítica é importante para se compreender, principalmente, o contexto em que os documentos são elaborados e de que maneira ocorrem as articulações entre os autores dos textos.

A esse respeito, Shiroma, Campos e Garcia (2005) fazem importantes considerações, ancoradas no modelo do policy cycle approach (abordagem do ciclo de políticas), de Bowe e Ball. Os autores afirmam que, nessa etapa:

Práxis Educativa, Ponta Grossa, v. 12, n. 2, p. 657-681, maio/ago. 2017 Disponível em: <http://www.revistas2.uepg.br/index.php/praxiseducativa > 
B. contexto de produção de textos: incluem documentos oficiais que 'representam' a política, a narrativa que lhe dá suporte; textos políticos são normalmente articulados à linguagem do público em geral. Sua narrativa caracteriza-se pelo populismo, senso comum e apelo à razão política. Cumpre lembrar que os textos representam a política, mas não é a política. Essa representação pode adquirir várias formas: textos oficiais e documentos políticos. Estes textos serão lidos, interpretados, por vezes mal interpretados, compreendidos ou não, e reinterpretados. 'Embora desejem, os autores não podem ter controle sobre os significados que serão atribuídos aos seus textos. Parte dos textos pode ser rejeitada, excluída, ignorada, deliberadamente mal entendida' (BOWE; BALL, 1992, p. 22). (SHIROMA; CAMPOS; GARCIA, 2005, p. 434, grifos dos autores).

Essa lógica, que não atinge apenas a Graduação em Educação Social, mas faz parte de toda reestruturação no Ensino Superior europeu, direciona a formação, enaltecendo os aspectos voltados à prática do futuro profissional. Esse movimento é o exemplo ideal do processo de internacionalização da educação, que, de maneira crítica, pode ser compreendido dentro da lógica descrita por Roger Dale (2004) quanto à existência de uma Agenda Globalmente Estruturada para Educação, que visa impor um padrão de Educação dentro do modelo capitalista. É aí o cuidado que se deve ter para pensar a formação profissional, pois os fundamentos que estão nas origens das orientações do Espaço Europeu de Ensino Superior se pautam no documento denominado, por Jacques Delors, Educação: um tesouro a descobrir, relatório de 1999 da Comissão Internacional sobre Educação para o Século XXI, da UNESCO.

Contudo, essa reformulação que acometeu os países da União Europeia teve uma consequência muito importante para o campo da Pedagogia Social na Espanha, pois resultou na reestruturação dos cursos de graduação até então existentes, organizando e elevando o status da formação do Educador Social para Cursos de Graduação em Educação Social, e não mais as antigas diplomaturas.

Seguindo as considerações pertinentes a essa pesquisa, acreditamos que essa dualidade entre o que é teórico e o que é prático seja algo que esteja na origem da Pedagogia Social. Questões foram apontadas anteriormente, por meio dos estudos de Xavier Úcar e Jacob Kornbeck, os quais contribuem para pensar a respeito ${ }^{1}$.

Os argumentos de Jan Storo (2012) colaboram para essa reflexão de maneira específica, pois suas pesquisas problematizam exatamente a relação entre teoria e prática no campo da Pedagogia Social. Em seu texto The difficult conection between theory and practice in Social Pedagogy, ele aprofunda essa questão. Um questionamento proposto por Storo que interessa a este estudo é justamente sobre a possível existência de uma crise no processo de formação dos Pedagogos Sociais e Trabalhadores Sociais no que se refere à dualidade entre teoria e prática. O autor descreve essa questão de maneira ampla, entendendo que essa crise pode estar alocada no âmbito do trabalho do profissional. Para o autor, quando os profissionais não identificam que seu trabalho é descrito ou explicado por uma teoria, e que eles não possuem determinado suporte teórico, a crise pode ser identificada subentendendo-se que a prática não está suficientemente compreendida dentro dos fundamentos que embasam teoricamente a profissão.

Storo (2012) segue explicando que a teoria da Pedagogia Social pode explicar os fatos e fenômenos observados nas situações práticas, o que é fundamental, pois o profissional precisa entender o que eles/elas estão fazendo e porque estão fazendo. $O$ autor defende que o profissional tenha condições de desenvolver seu trabalho e refletir sobre ele, tendo a possibilidade de criação de novos elementos para o seu fazer laboral, ocupando a teoria condição sine qua non nesse processo. Ele afirma que o profissional precisa tanto de uma teoria que seja

1 Também a respeito das relações entre associações profissionais e meio acadêmico no contexto espanhol, é importante a contribuição de Esteban, Caride Gomez e Úcar (2013).

Práxis Educativa, Ponta Grossa, v. 12, n. 2, p. 657-681, maio/ago. 2017 Disponível em: <http://www.revistas2.uepg.br/index.php/praxiseducativa > 
explicativa como também uma teoria que oriente suas ações, ou seja, uma teoria que possibilite o entendimento e o acesso à informação, bem como uma teoria que direcione a intervenção. Para o pesquisador, essa relação deve propiciar mais consciência sobre o que está sendo colocado em prática. Esses argumentos não esgotam as possíveis análises dos dados obtidos. Contudo algumas considerações são importantes, pois contribuem para uma possível avaliação da formação dos Educadores Sociais espanhóis.

Com os estudos realizados em nível de Mestrado (RIBAS MACHADO, 2010) e, também, agora para o doutorado, é possível afirmar que a Pedagogia Social surge a partir da constatação de fatores que expressavam a realidade social, que, na época das suas primeiras sistematizações, foram identificados no contexto alemão, instigando importantes Pedagogos a refletir teoricamente sobre a questão. Estes buscaram precedentes de práticas educativas sociais, encontrando em Pestalozzi uma grande referência, como aponta Lorenzo Luzuriaga (1984).

No caso espanhol, também foram as questões sociais que motivaram intelectuais a buscarem concepções de uma educação que fosse além do que estava estabelecido como padrão. É interessante constatar que a motivação para se criar e desenvolver a Pedagogia Social na Espanha surgiu de práticas educativas realizadas junto a crianças e adolescentes. Posteriormente, é que outras faixas etárias foram sendo consideradas nas intervenções da Educação Social.

Concluímos, portanto, que a prática motivou o desenvolvimento da teoria, que, por sua vez, permitiu reconhecer a existência de outras perspectivas educativas. Sem a elaboração teórica e sistematizada que forjou a Pedagogia Social como uma ciência e uma disciplina, as práticas educativas sociais não teriam o reconhecimento como área de atuação de profissionais, que, neste trabalho, são chamados de Educadores Sociais. É importante também reconhecer que as práticas desenvolvidas pelos Educadores Sociais no decorrer dos tempos, em diferentes contextos, possibilitaram que a Pedagogia Social continuasse a existir, sendo reelaborada a partir de novas necessidades e de transformações das relações sociais.

Podemos afirmar, então, a partir das análises realizadas, que a disciplina estudada expressa uma concepção de Pedagogia Social, que serve como fundamentação teórica essencial para a formação do Educador Social. A centralidade da Pedagogia Social na formação do Educador Social está em proporcionar a ele uma visão de vida, de homem e de mundo diferente da visão proporcionada pela Educação pretensamente hegemônica. Nesse sentido, deve-se admitir que ela possui preceitos da práxis potencialmente úteis e necessários para promover os enunciados consignados nos objetivos e nas competências das ementas analisadas.

Essa reflexão permite que países que estão na fase de construção e de busca por uma identidade da Pedagogia Social, como área de pesquisa, de formação e de atuação profissional, possam ter parâmetros para fomentar discussões curriculares que levem a uma sólida formação de seus Educadores Sociais, como é o caso do Brasil.

\section{Referências}

ANECA. Agencia Nacional de Evaluación de la Calidad y Acreditación. Libro Blanco: título de grado en Pedagogía y Educación Social. V1. Espanha, 2005.

DALE, R. Globalização e educação: demonstrando a existência de uma "Cultura Educacional Mundial Comum" ou localizando uma "Agenda Globalmente Estruturada para a Educação"? Educação \& Sociedade, Campinas, v. 25, n. 87, p. 423-460, maio/ago. 2004. 
DECLARAÇÃO DE BOLONHA. Declaração conjunta dos Ministros da Educação europeus reunidos em Bolonha a 19 de junho de 1999. 1999. Disponível em: $<$ http://www.ufabc.edu.br/images/stories/pdfs/declaracaodebolonhaportugues.pdf $>$. Acesso em: 5 jun. 2017.

DELORS, J. Educação, um tesouro a descobrir: Relatório para a UNESCO da Comissão Internacional sobre Educação para o século XXI. UNESCO, 1999.

ESTEBAN, J. O.; CARIDE GOMEZ, J.; ÚCAR, X. La Pedagogía Social em la formación profesionalización de los educadores y las educadoras sociales, o de cuando el passado construye futuros. Revista de Educación Social, n. 17, jul. 2013.

GARCIA GARRIDO, J. L. Fundamentos de Educación Comparada. Madri: Dikynson, 1986.

LUZURIAGA, L. História da educação e da pedagogia. 15. ed. São Paulo: Nacional, 1984.

PEREZ SERRANO, G. Investigación Cualitativa: métodos y técnicas. Buenos Aires: Editorial Docencia, 2003.

PEREZ SERrANO, G. Pedagogía Social/Educación Social: construcción científica e intervención práctica. Madrid: Narcea, 2004.

RIBAS MACHADO, É. O desenvolvimento da Pedagogia Social sob a perspectiva comparada: o estágio atual no Brasil e Espanha. 2014. 304 f. Tese (Doutorado em Educação) Universidade de São Paulo, São Paulo, 2014.

QUINTANA CABANAS, J. M. Antecedentes históricos de la educación social. In: PETRUS, A. (Org.). Pedagogia Social. Espanha: Ariel, 1997. p. 68-91.

SÁEZ CARRERAS, J. El educador social. Murcia: Universidad de Murcia, 1993.

SHIROMA, E.; CAMPOS, R. F.; GARCIA, R. M. C. Decifrar textos para compreender a política: subsídios teórico-metodológicos para análise de documentos. Perspectiva, Florianópolis, v. 23, n. 2, p. 427-446, jul./dez. 2005.

STORO, J. The difficult connection between theory and practice in Social Pedagogy. International Journal of Social Pedagogy, Anglesey v. 1, n. 1, 2012.

Recebido em 20/12/2016

Versão corrigida recebida em 10/02/2017

Aceito em 05/06/2017

Publicado na versão online em 03/07/2017 